\title{
Carbon Trust invests in ultrahigh temperature sensor
}

\author{
The Carbon Trust, a not-for-profit \\ company set up by the UK Government \\ to accelerate the move to a low-carbon \\ economy, has invested in Oxsensis, a \\ UK developer of optical-fibre-based \\ temperature and pressure sensors. The new \\ support has helped Oxsensis to raise a total \\ of $£ 3$ million in its latest funding round, \\ with the Carbon Trust now joining existing \\ investors Albion Ventures, Seven Spires, \\ Frog Capital and Rainbow Seed Fund. \\ Oxsensis, which was founded in 2003, \\ has developed a family of temperature \\ and pressure sensors that can be used \\ in hostile environments such as gas \\ turbines, aircraft engines and nuclear \\ reactors. Based on single-crystal sapphire, \\ the sensors are capable of measuring \\ heat and pressure in extremely harsh \\ conditions. Oxsensis' sensors are \\ capable of operating at temperatures
}

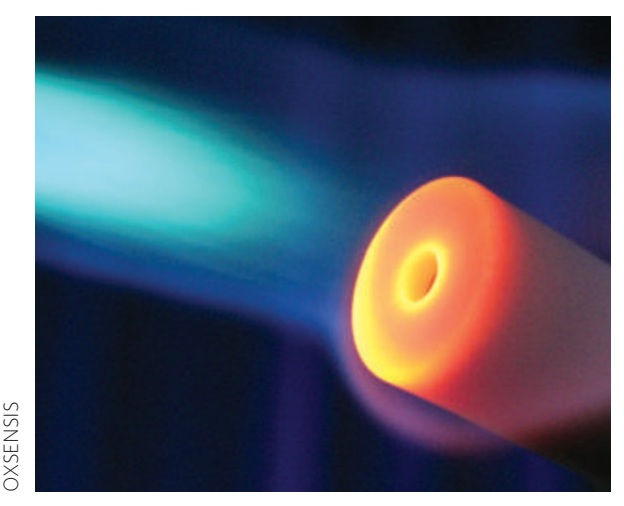

exceeding $1,000{ }^{\circ} \mathrm{C}$, making them attractive for use in aerospace and powergeneration applications.

"The sensor head is essentially a small Fabry-Pérot interferometer with a sapphire membrane," explains David Gahan, CEO of Oxsensis. "Using silicon-integrated optics, we have also developed miniaturized interrogation technology, which allows multiparameter sensing over multiple channels in a small package."

Although much of the technology behind Oxsensis' silicon-integrated optics system was developed in-house at Rutherford Appleton Laboratories in Oxfordshire, UK, where the company is based, much of the technology used in the sensor was purchased from Bookham, a developer of integrated optics for telecommunications.

The funding will support business development and help Oxsensis to further enhance its sensor technology. The company is already progressing from technology development to fullscale commercialization, with long-term customer trials currently underway.

\section{Business is booming for fibre-optic gyros}

Honeywell and KVH Industries have both recently made announcements about contracts for their fibre-optic gyroscope technologies. Honeywell's Air Data Inertial Reference System (ADIRS) has become the standard inertial reference system for the Airbus A320, A330/A340 and A380 family of aircraft, and $\mathrm{KVH}$ has received a $\$ 2$ million order for its TACNAV II tactical navigation system.

Honeywell's ADIRS, which provides navigational data using ring laser gyroscopes and quartz accelerometers, provides critical flight control and navigation information to aircraft systems by autonomously tracking aircraft motion. ADIRS' advanced navigation accuracy is a key component for nextgeneration air traffic management as it enables more direct routing by following precise satellite-based navigation approaches to airports, thus reducing flight delays and fuel costs.

KVH's TACNAV II tactical navigation system is designed for military applications, particularly for battle management and weapon systems. With a precision fibreoptic gyroscope and an optional compass sensor providing complete backup for its global positioning system, the TACNAV II can integrate with a host of applications, including navigation and data consolidation for battle management systems. Shipment of this latest order is expected to begin in the second quarter of 2011 and conclude in early 2014.

\section{Fibre sensors monitor mining pipeline}

The Swiss structural health monitoring specialist Smartec, a subsidiary of the metrology firm Roctest, is providing a fibre-optic pipeline leak detection system for a major mining operation in Chile. In conjunction with its distributor, Geomediciones, the group is in the process of installing the system for a pair of $154 \mathrm{~km}$ parallel pipelines that will transport mining concentrates and industrial salt water from the Esperanza mine to a Pacific port. The mine produces concentrates containing gold, copper, silver and molybdenum, which are then transported via the pipeline for water extraction, storage and shipment. According to Roctest, the contract is worth around 350,000 Swiss francs.

"This project is an excellent example of an application of fibre-optic sensors that would not be feasible using any other technology," said François Cordeau, president and CEO of Roctest. "The customer is very interested in using the most advanced technology available to protect the local environment. Our solution will enable them to monitor every single metre of the pipeline for leaks, and take corrective action the moment any issues are detected. This level of monitoring is virtually unprecedented in the mining industry."

Roctest acquired Smartec in 2006 and also owns Canadian firm FISO technologies, another fibre-optic sensor manufacturer. In its recently announced financial results for the first quarter of 2010 , Roctest reported a $4.6 \%$ year-on-year increase in revenue to $\$ 6.06$ million but a net loss of $\$ 60,000$ for the period.

\section{Acorn Energy invests in 4D seismic technology}

Acorn Energy has made a strategic investment in US Sensor Systems Inc. (USSI), a developer of fibre-optic seismic monitoring systems. USSI is using Acorn's $\$ 500,000$ investment to conduct field trials comparing its new fibre-optic geophone technology to current best-in-class conventional geophones.

USSI's fibre-optic geophone system is designed to provide the industry with the tools needed to make the transition from $3 \mathrm{D}$ to $4 \mathrm{D}$ seismic monitoring feasible - an evolution that is expected to greatly increase extraction from existing oilfields.

Acorn has so far acquired approximately $10 \%$ of USSI through such investments, and has options for acquiring up to $84 \%$ for aggregate consideration of approximately $\$ 6.1$ million in cash and stocks by May 2011 . 